\title{
Evaluation of the clinical value of ELISA based on MPT64 antibody aptamer for serological diagnosis of pulmonary tuberculosis
}

\author{
Changtai Zhu ${ }^{1,2+}{ }^{\text {, Jinming Liu }}{ }^{3+}$, Yang Ling ${ }^{1}$, Hua Yang ${ }^{2}$, Zhonghua Liu², Ruijuan Zheng ${ }^{2}$, Lianhua Qin ${ }^{2,4^{*}}$ \\ and Zhongyi $\mathrm{Hu}^{2,4^{*}}$
}

\begin{abstract}
Background: Presently, tuberculosis (TB) poses a global threat to human health. The development of reliable laboratory tools is vital to the diagnosis and treatment of TB. MPT64, a protein secreted by Mycobacterium tuberculosis complex, is highly specific for TB, making antibody to MPT64 a reagent specific for the diagnosis of TB.

Method: Antibody to MPT64 was obtained by a combination of genetic engineering and immunization by the system evolution of ligands by exponential enrichment. A high-affinity aptamer of antibody to MPT64 was selected from a random single-stranded DNA library, and a sandwich ELISA method based on this aptamer was developed. This ELISA method was used to detect TB in 328 serum samples, 160 from patients with pulmonary TB (PTB) and 168 from non-tuberculous controls.

Results: The minimum limit of detection of the ELISA method was $2.5 \mathrm{mg} / \mathrm{L}$, and its linear range varied from $10 \mathrm{mg} / \mathrm{L}$ to $800 \mathrm{mg} / \mathrm{L}$. Its sensitivity, specificity, positive likelihood ratio, negative likelihood ratio and area under the curve, with 95 \% confidence intervals, were $64.4 \%$ (56.7\%-71.4\%), $99.4 \%$ (96.7 \%-99.9\%), 108.2 (15.3-765.9), 0.350 $(0.291-0.442)$ and $0.819(0.770-0.868)$, respectively. No significant difference in sensitivity was observed between sputum smear positive $(73 / 112,65.2 \%)$ and negative $(30 / 48,62.5 \%)$ individuals.
\end{abstract}

Conclusions: This sandwich ELISA based on an MPT64 antibody aptamer may be useful for the serological diagnosis of PTB, both in sputum smear positive and negative patients.

Keywords: MPT64 antibody, System evolution of ligands by exponential enrichment (SELEX), sSDNA, Aptamer, Tuberculosis

\section{Background}

Being a contagious disease, tuberculosis (TB) poses a global threat to human health. The World Health Organization [1] reported that in 2010, there were 8.8 million (range, 8.5-9.2 million) incident cases of TB, 1.1 million (range, 0.9-1.2 million) deaths from TB among HIVnegative individuals and 0.35 million (range, 0.32-0.39 million) deaths from HIV-associated TB. In China,

\footnotetext{
*Correspondence: qlh1013@yahoo.com.cn; shtblab@163.com

${ }^{\dagger}$ Equal contributors

${ }^{2}$ Shanghai Key Laboratory of Tuberculosis, Shanghai Pulmonary Hospital, Tongji University School of Medicine, Shanghai 200433, China

${ }^{4}$ Shanghai Key Laboratory of Tuberculosis, Shanghai Pulmonary Hospital, Tongji University School of Medicine, No. 507 Zhengmin Rd, Shanghai 200433, People's Republic of China

Full list of author information is available at the end of the article
}

dramatic reductions in TB cases and deaths have been achieved. Although the Stop TB Partnership target of halving TB prevalence rates by 2015 compared with 1990 was unlikely to be achieved globally, this target had already been reached in the Americas and was close to being reached in the Western Pacific Region [1]. Two important factors have contributed to the resurgence and morbidity of TB: (i) the emergence of multi-drug-resistant and extensively drug-resistant strains of Mycobacterium tuberculosis and (ii) the increasing incidence of HIV globally [2-6]. Most patients with TB have pulmonary TB (PTB), and developing reliable laboratory tools is vital to the diagnosis and treatment of PTB [7].

Antibody to MPT64 has been shown to bind MPT64 protein [8], a highly specific protein secreted by $M$.

\section{Ciomed Central}


tuberculosis (MTB) complex, which includes $M$. tuberculosis, M. bovis and M. africanum [9-11]. Therefore, this antibody may be useful in the detection of TB. We describe here the use of the systematic evolution of ligands by exponential enrichment (SELEX) technique to develop a sandwich ELISA method based on an MPT64 antibody aptamer for the diagnosis of PTB.

\section{Materials and methods}

\section{Ethics Statement}

All patients were treated in accordance with the Helsinki Declaration on the participation of human subjects in medical research. The study protocol was approved by the Tongji University Ethics Committee (permit number: K08-018), and informed consent was obtained from each participant. Animal studies were approved by the Second Military Medical University Animal Care and Ethics Committee [approval ID: SYXK/2007-0003].

\section{Preparation of antibody to MPT64}

Based on the sequence of the $\mathrm{H} 37 \mathrm{Rv} \mathrm{TB}$ reference strain encoding the MPT64 gene (accession number: NC_000962), we designed forward (5'-CCCATATG CGCATCAAGATCTTCAT-3') and reverse (5'-CCA AGCTTGGCCAGCATCGAGTCG-3') primers, containing Nde I and Hind III restriction sites, respectively. PCR amplification with these primers was performed using $\mathrm{H} 37 \mathrm{Rv}$ nucleic acid as template. Subsequently, the purified PCR product was inserted into the $\mathrm{T}$ vector using ligase. After digestion with restriction enzyme, pMD18-MPT64 was to pET21a using T4 ligase and the pET21a-MPT64 expression plasmid was used to transform BL21 (DE3) competent cells. Positive recombinant clones were identified by DNA sequencing.

A recombinant clone was inoculated overnight into the Luria Bertani medium at $37^{\circ} \mathrm{C}$. The resultant bacteria were lysed with ultrasound and the medium was centrifuged. The sediment was resuspended in $10 \%$ Triton-X 100 buffer, and MPT64 protein was purified on a nickelagarose column. MPT64 protein was identified by sodium dodecyl sulfate polyacrylamide gel electrophoresis [12] [Figure 1].

Rabbits were immunized with MPT64 protein by subcutaneously injecting a suspension of $0.5 \mathrm{ml}$ phosphatebuffered saline (PBS] containing $0.5 \mathrm{~g} / \mathrm{L}$ MPT64 protein and $0.5 \mathrm{ml}$ Freund's complete adjuvant into six sites on the back of each rabbit. On days 14, 24, 34, and 44, each rabbit was injected with the same dose of MPT64 protein and Freund's incomplete adjuvant. Rabbit serum was collected, and MPT64 antibody was purified on a CNBr-activated Sepharose 4B column, with the purified antibody identified by western blotting [Figure 2]. The details of the method have been described previously
[13]. Purified antibody was quantified by the Bradford method [14].

\section{Construction of a random single-stranded DNA (ssDNA) library}

Using the primers 5'-GGGAGCTCAGAATAAACGCT CAA-3' (forward) and 5'-Biotin-TTCGACATGAGGCCC GGATC-3' (reverse), a 78-mer ssDNA library was constructed with the sequences, 5' -GGGAGCTCAGAA TAAACGCTCAA-AN35-CGACATGAGGCCCGGATC3 , with the middle 35 sequences being random. The random ssDNA library and primers were synthesized commercially by Shanghai Sangon Company.

\section{Selection of MPT64 antibody aptamer}

The ssDNA library was optimized by PCR amplification to obtain a double-stranded DNA (dsDNA) library. Furthermore, the ssDNA library was constructed by using asymmetric PCR. The amplified product was purified with a phenol-chloroform-isoamyl alcohol mixture (volume ratios, 25:24:1)]. ELISA plates coated with bovine serum were used to remove non-specific nucleotides from the ssDNA library and the purified ssDNA library added to microplates coated with antibody to MPT64. The plates were washed six times with SELEX buffer. SELEX eluate $(20.0 \mathrm{mM}$ Tris- $\mathrm{HCl}, 4.0 \mathrm{mM}$ guanidinium isothiocyanate, $1.0 \mathrm{mM}$ 1,4-dithiothreitol; $\mathrm{pH}$ 8.3) was added and allowed to incubate at $80^{\circ} \mathrm{C}$ for $10 \mathrm{~min}$. The ssDNA was extracted with a phenol-chloroform-ethanol mixture. Using the extracted ssDNA as a template, asymmetric PCR was performed. Then, the next round of screening was performed. The parameters of the SELEX assay are shown in Table 1.

After 12 rounds of aptamer selection, the absorbance of the ssDNA reached its maximum value and a single electrophoretic stripe was displayed. This indicated that the purified ssDNA library with high affinity to the antiMPT64 antibody was saturated. The PCR products were purified using the TIANgen Midi Purification Kit (TIANgen Biotech [Beijing] Co., Ltd.) and subcloned into a pMD 18-T vector with a TA cloning kit (TaKaRa, Dalian, China). The resultant bacteria were used to transform Escherichia coli DH5 $\alpha$ strains, and individual bacterial clones were selectively sequenced by a commercial company (Sangon, Shanghai, China).

The affinity of the selected ssDNA aptamers was measured by ELISA. Polystyrene microplates were coated overnight at $4^{\circ} \mathrm{C}$ with $10 \mu \mathrm{g} /$ well of anti-MPT64 antibody in $100 \mu \mathrm{l} 0.1 \mathrm{M} \mathrm{NaHCO}_{3}$ (pH 9.4), washed four times with washing buffer (PBS containing $0.05 \%$ Tween 20, pH 7.4) and incubated for 1 hour at room temperature with $200 \mu \mathrm{l}$ of blocking buffer. The microplates were washed once with washing buffer and $1.0 \mu \mathrm{g} /$ well of biotin-labeled DNA aptamer in a binding 


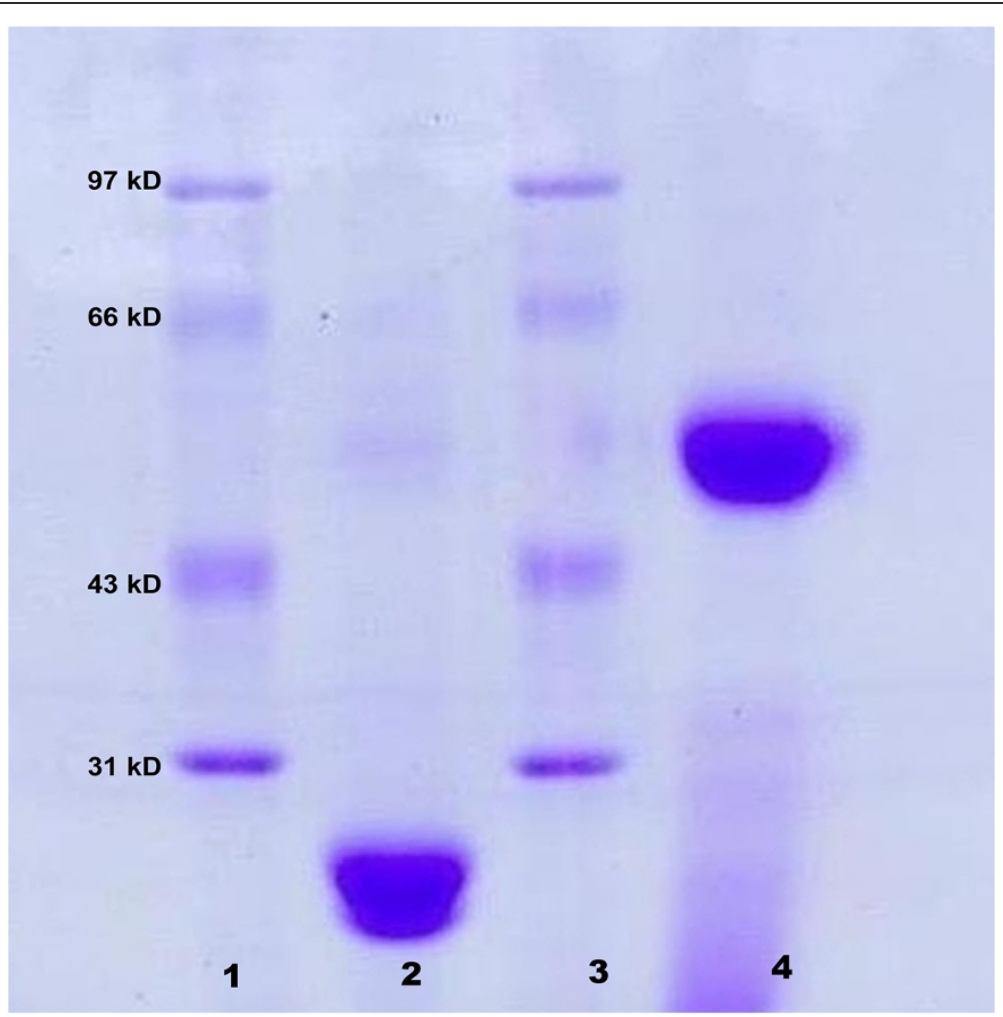

Figure 1 SDS-PAGE analysis of MPT64 protein obtained by genetic recombination. Lanes 1 and 3: markers; Lane 2: purified MPT64 protein (24 kD); Line 4: purified polyclonal antibody to MPT64 (50 kD).

buffer (SHCMK) containing $20.0 \mathrm{mM}$ Hepes, $\mathrm{pH}$ 7.35, $1.0 \mathrm{mM} \mathrm{CaCl}, 120 \mathrm{mM} \mathrm{KCl}$ and $1.0 \mathrm{mM} \mathrm{MgCl}_{2}$ was added. The aptamers and MPT64 antibody were allowed to react at $37^{\circ} \mathrm{C}$ for $40 \mathrm{~min}$. The plates were washed six times with washing buffer (SHCMK $+0.05 \%$ Tween 20) and incubated at $37^{\circ} \mathrm{C}$ for $30 \mathrm{~min}$ with $100 \mu \mathrm{l} /$ well of streptavidin-horseradish peroxidase (Sigma, USA) diluted 1:1000 in PBS. Finally, the plate was washed six times with PBST and $100 \mu \mathrm{l}$ of $1.0 \mathrm{mM}$ tetramethylbenzidine in citrate buffer $(0.1 \mathrm{M}, \mathrm{pH} 4.25)$, with $2.0 \mathrm{mM}$ $\mathrm{H}_{2} \mathrm{O}_{2}$ added as substrate in a ratio of 1:20. The

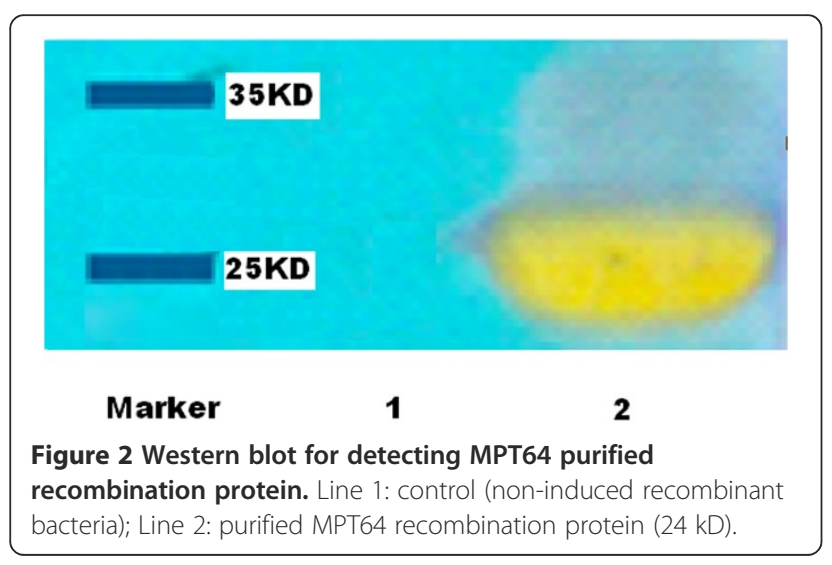

enzymatic reaction was stopped 5 min later by the addition of $50 \mu \mathrm{l} 1.0 \mathrm{M} \mathrm{H}_{2} \mathrm{SO}_{4}$ and optical density (OD) of $450 \mathrm{~nm}$ was measured spectrophotometrically.

\section{Sandwich ELISA based on the anti-MPT64 antibody aptamer}

We assessed the secondary structures of the aptamers using sequencing results and the DNAMAN version 4.0 (Lynnon Corporation, Quebec, Canada). The aptamer with highest affinity to the anti-MPT64 antibody was regarded as the capture and detection aptamer by ELISA. Each microplate well was coated with $0.1 \mu \mathrm{g}$ of the capture aptamer, and the 5 ' end of the detection aptamer was labeled with biotin. Based on the detection of purified anti-MPT64 antibody at different dilution ratios, the minimum limit of detection and the linear range of this ELISA method were determined.

\section{Serum samples, participant characteristics and validation} of the ELISA

We obtained 328 serum samples, 160 from patients with definite PTB and 168 from non-tuberculous controls including 78 healthy volunteers and 90 nontuberculous patients. All participants were confirmed as being serologically HIV-negative. Of the 90 nontuberculous patients, 35 had pneumonia, 40 had lung 
Table 1 Parameters during each round of the SELEX assay

\begin{tabular}{|c|c|c|c|c|}
\hline SELEX rounds & Antibody ( $\mu \mathrm{g} /$ well) & ssDNA( $\mu \mathrm{g} /$ well) & $\begin{array}{l}\text { Reaction time in BSA- } \\
\text { blocked blank wells ( } \mathrm{min})\end{array}$ & $\begin{array}{l}\text { Reaction time in } \\
\text { antibody-coated wells } \\
\text { (min) }\end{array}$ \\
\hline 1 & 1 & 0.5 & 15 & 60 \\
\hline 2 & 0.5 & 0.5 & 20 & 60 \\
\hline 3 & 0.25 & 0.5 & 20 & 60 \\
\hline 4 & 0.25 & 0.1 & 30 & 45 \\
\hline 5 & 0.1 & 0.1 & 30 & 45 \\
\hline 6 & 0.25 & 0.1 & 30 & 45 \\
\hline 7 & 0.1 & 0.1 & 45 & 30 \\
\hline 8 & 0.1 & 0.05 & 45 & 30 \\
\hline 9 & 0.05 & 0.05 & 45 & 30 \\
\hline 10 & 0.05 & 0.025 & 60 & 20 \\
\hline 11 & 0.025 & 0.025 & 60 & 20 \\
\hline 12 & 0.025 & 0.01 & 60 & 15 \\
\hline
\end{tabular}

cancer, and 15 had lung abscesses and other conditions. Lowenstein-Jensen (L-J) culture was performed on all of these subjects to rule out TB.

The median ages of the PTB (31 years; range, 1273 years; IQR [interquartile range], 17-45 years) and non-tuberculous controls (28 years; range, 14-69 years; IQR, 18-42 years) did not differ significantly $P>0.05$ ). Patients were diagnosed with PTB by physicians based on the criteria of the Chinese Anti-tuberculosis Association, mainly including continuous fever and cough for more than 3 weeks, abnormal chest X-ray, weight loss and the demonstration of $\mathrm{TB}$ in sputum by L-J culture and standard biochemical identification tests. Sputum smear examinations for PTB and nontuberculous patients were performed using the ZiehlNeelsen method at the same time as L-J culture inoculation.

\section{Statistical analysis}

The sensitivity, specificity, positive likelihood ratio (PLR), negative likelihood ratio (NLR) and area under the curve (AUC), each with $95 \%$ confidence interval (CI), were calculated. All statistical analyses were performed using Stata version 9 (Statacorp, Texas, USA).

\section{Results}

Affinity, sequencing and secondary structure of ssDNA aptamers

The OD values of ssDNA aptamers against MPT64 antibody (reflecting affinity) ranged from 0.55 to 1.62 [Table 2]. We elected MPT64-A1, which had a higher affinity (OD value: 1.62) than did the capture aptamer for ELISA. The sequences of aptamer included forward fixed sequences (5'- GGGAGCTCAGAATAAACGCTCAAA3'), random sequences (5'- AACGCTCAAGAGGCCCG GATC-3') and reverse fixed sequences (5'-TTCGAC ATGAGGCCCGGATC-3'). The DNAMAN package predicted that the secondary structure of MPT64-A1 is a stem-loop structure, similar to a large pocket [Figure 3].

Minimum detection limit and linear range of this ELISA Based on the detection of the purified MPT64 antibody at different dilution ratios, we found that the limit of detection of this method was $2.5 \mathrm{mg} / \mathrm{L}$ and the linear range varied from $10 \mathrm{mg} / \mathrm{L}$ to $800 \mathrm{mg} / \mathrm{L}$ [Figure 4].

Performance of the ELISA for serological diagnosis of PTB In diagnosing PTB, this method had a sensitivity, specificity, PLR, NLR, and AUC, with $95 \% \mathrm{CI}$, of $64.4 \%$ (56.7 \%-71.4 \%), $99.4 \%$ (96.7 \%-99.9\%), 108.2 (15.3-

Table 2 Affinities of ssDNA aptamers to anti-MPT64 antibody

\begin{tabular}{|c|c|c|c|c|c|}
\hline Name of aptamers & OD value & Name of aptamers & OD value & Name of aptamers & OD value \\
\hline MPT64-A1 & 1.62 & MPT64-A5 & 0.93 & MPT64-A9 & 1.24 \\
\hline MPT64-A2 & 0.82 & MPT64-A6 & 0.55 & MPT64-A10 & 1.12 \\
\hline MPT64-A3 & 0.78 & MPT64-A7 & 0.90 & MPT64-A11 & 1.10 \\
\hline MPT64-A4 & 0.96 & MPT64-A8 & 1.33 & MPT64-A12 & 1.06 \\
\hline
\end{tabular}




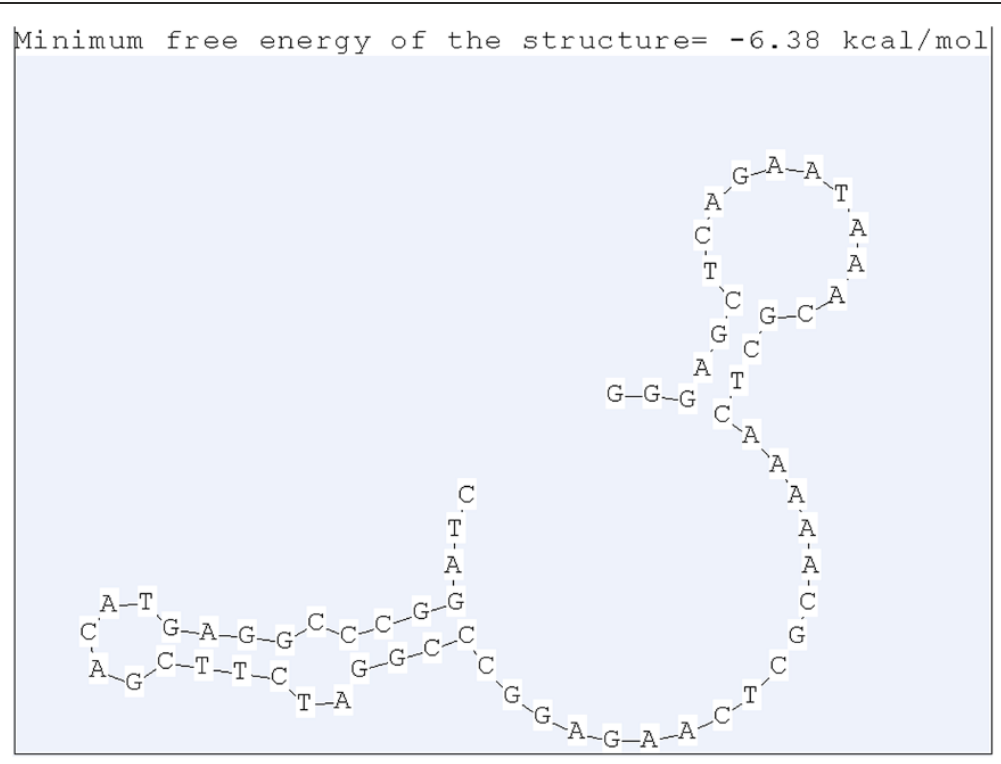

Figure 3 Secondary structure of the aptamer MPT64-A1 predicted by DNAMAN.

$765.9), 0.35(0.291-0.442)$, and $0.819(0.770-0.868)$, respectively [Table 3]. Its sensitivity was similar for sputum smear positive $(73 / 112,65.2 \%)$ and negative (30/48, $62.5 \%)$ individuals [Table 4].

\section{Discussion}

MPT64 protein is one of the main filtrate proteins secreted by MTB complex at an early stage. This protein is encoded by the Rv1980c gene, contains 228 amino acids and has a molecular mass of about $24,000 \mathrm{Da}$. It is a specific protein, being secreted only by the MTB complex [15-18]. In skin tests, this protein has a sensitivity of $87.8 \%$ and a specificity of $100 \%$ for diagnosing active TB $[19,20]$. Except for the MTB complex, bioinformatics showed no epitopes similar to MPT64 protein, indicating its uniqueness. Furthermore, few BCG vaccines express MPT64 protein [17], suggesting that anti-MPT64 antibody may be specific for the diagnosis of TB. Therefore, using a combination of immunization and genetic engineering with SELEX, we developed a sandwich ELISA method based on an anti-MPT64 antibody aptamer for the diagnosis of PTB.

SELEX [21,22] is a combinatorial chemistry technique used in molecular biology to produce single-stranded

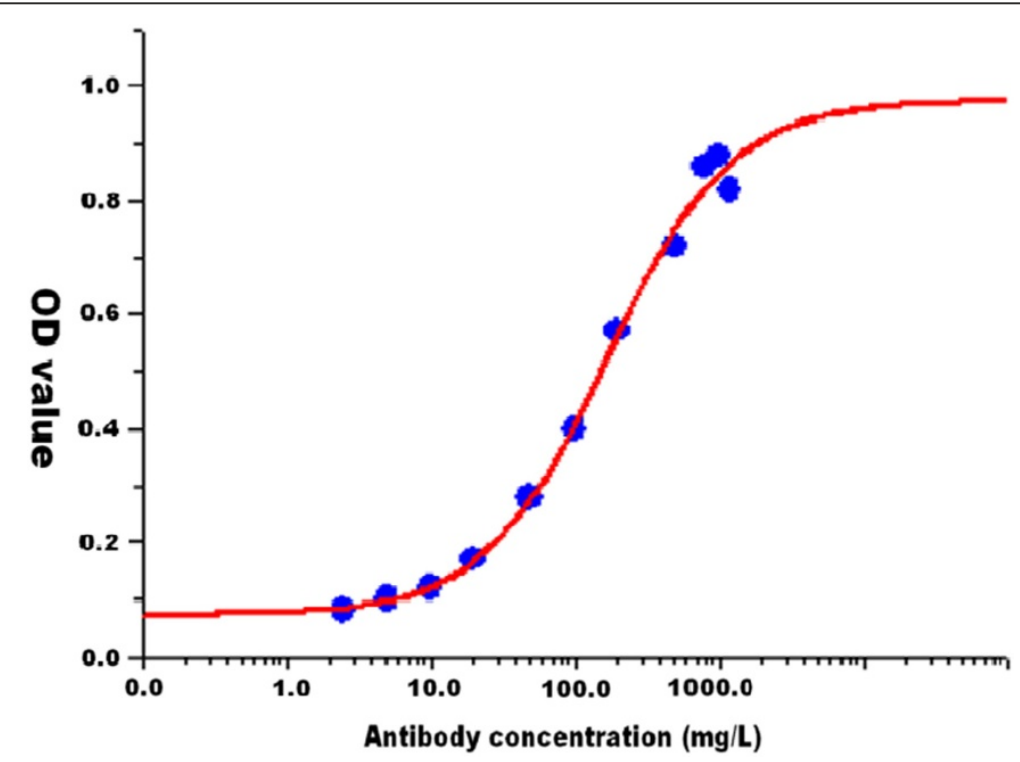

Figure 4 Linear range and minimum detection limit of the ELISA method. 
Table 3 Performances of ELISA based on an anti-MPT64 antibody aptamer for serological diagnosis of pulmonary tuberculosis

\begin{tabular}{|c|c|c|c|c|c|c|c|c|}
\hline & & \multirow{2}{*}{$\begin{array}{l}\text { PTB } \\
(n=160)\end{array}$} & \multirow{2}{*}{$\begin{array}{l}\text { Non-TB } \\
(n=168)\end{array}$} & \multicolumn{5}{|c|}{ Testing performances } \\
\hline & & & & $\begin{array}{l}\text { Sensitivity } \\
(\%, 95 \% \mathrm{Cl})\end{array}$ & $\begin{array}{l}\text { Specificity } \\
(\%, 95 \% \mathrm{Cl})\end{array}$ & $\begin{array}{l}\text { PLR } \\
(95 \% \text { Cl) } \\
\end{array}$ & $\begin{array}{l}\text { NLR } \\
(95 \% \text { Cl) }\end{array}$ & AUC \\
\hline \multirow[t]{2}{*}{ ELISA } & $\begin{array}{l}\text { Positive } \\
(n=104)\end{array}$ & 103 & 1 & 64.4 & 99.4 & 108.2 & 0.358 & 0.819 \\
\hline & $\begin{array}{l}\text { Negative } \\
(n=224)\end{array}$ & 57 & 167 & $(56.7-71.4)$ & $(96.7-99.9)$ & $(15.3-765.9)$ & $(0.291-0.442)$ & $(0.770-0.868)$ \\
\hline
\end{tabular}

PLR: positive likelihood ratio. NLR: negative likelihood ratio. Cl: confidence interval. PTB: pulmonary tuberculosis. AUC: area under the curve.

DNAs or RNAs that specifically bind ligands. SELEX can be used to select high affinity aptamers against target ligands and to obtain specific aptamers from an in vitro pool of random aptamers. SELEX methods have improved drastically in recent years, and several innovative SELEX approaches have been developed, including counter-SELEX , tissue-SELEX, cell SELEX (TECS-SELEX), fluorescent bead SELEX (FluMag-SELEX), capillary electrophoresis SELEX (CE-SELEX), neutral SELEX, and non-SELEX [2331]. SELEX was recently used to develop a aptamers against counterpart target ligands, such as Campylobacter jejuni [32]; C-reactive protein [33]; heterogeneous nuclear ribonucleoproteins (hnRNPs) A1 [34]; hepatitis C virus envelope glycoprotein E, botulinum neurotoxin [35]; the carboxyl terminus of Kirsten rat sarcoma viral oncogene homolog (K-RAS) protein [36], adenosine [37] and others. Some aptamers against cancer-related proteins, such as plateletderived growth factor, vascular endothelial growth factor (VEGF), human epidermal growth factor receptor 2, nuclear factor $\mathrm{\kappa B}$, tenascin- $\mathrm{C}$ and prostate-specific membrane antigen [24,38-40], have also been selected. Moreover, aptamers against whole cells, particularly cancer cells, have been selected [38,41-46]. The aptamers selected by SELEX were demonstrated to have potential clinical value [47-50]. For example, pegaptanib (Macugen), used to treat neovascular age-related macular degeneration, and the anti-VEGF aptamer pegaptanib used to treat human ocular vascular disease, have received approval by the US Food and Drug Administration [51,52]. In summary, SELEX has attracted widespread attention and the selected aptamers have been used in clinical diagnosis, treatment and drug development.

Functionally, an aptamer is similar to a protein antibody complex obtained following immunization. Among the advantages of aptamers over classical protein antibody complexes are (1) higher specificity and affinity; (2) its binding to a greater variety of target ligands, including biological macromolecules, small molecule organic compounds, inorganic ions, pathogenic microorganisms, and cells; (3) increased convenience and lower cost; and (4) greater stability, including storage at room temperature.

We have utilized the SELEX method to obtain aptamers against anti-MPT64 antibody in order to develop an ELISA method for the diagnosis of TB. Following 12 rounds of screening, we observed a single electrophoretic strip, indicating that the purified ssDNA library with a high affinity for anti-MPT64 antibody was saturated.

However, we observed differences in the affinities of the selected aptamers. Its OD showed that MPT64-A1 had the highest affinity of all aptamers, whereas DNA sequencing showed that absorbances for detecting affinity were relatively constant. We found only small differences among the absorbance values for aptamers with single base differences at the $5^{\prime}$, whereas differences in nucleotides at the stem-loop structure at the 3 ' end had significant effects on affinity to anti-MPT64 antibody. This suggested that the stem-loop structure may be the site at which aptamers bind to the MPT64 antibody. The secondary structure predicted by DNAMAN indicated that MPT64-A1 could form a stem-loop structure like a large pocket.

We found that the limit of detection of our ELISA method was $2.5 \mathrm{mg} / \mathrm{L}$, with a linear range varying from $10 \mathrm{mg} / \mathrm{L}$ to $800 \mathrm{mg} / \mathrm{L}$. This suggested that this method was sensitive and could have potential clinical value. ELISA had a high specificity (99.4 \%, 95 \% CI: $96.7 \%-99.9 \%)$ and PLR 108.2 (15.3-765.9) and was appropriate for diagnostic purposes. However, this method had a sensitivity of $64.4 \%$ (95 \% CI: $56.7 \%-71.4 \%$ ) and an NLR of 0.350 (95 \% CI:

Table 4 ELISA based on an anti-MPT64 antibody aptamer for serological diagnosis of pulmonary tuberculosis with sputum smear positive and negative patients

\begin{tabular}{|c|c|c|c|c|c|}
\hline & & \multicolumn{2}{|l|}{ Smear } & \multirow[t]{2}{*}{$x^{2}$} & \multirow{2}{*}{$\begin{array}{l}p \\
\text { value }\end{array}$} \\
\hline & & Positive $(n=112)$ & Negative $(n=48)$ & & \\
\hline \multirow[t]{2}{*}{ ELISA } & Positive $(n=103)$ & 73 & 30 & 0.105 & 0.746 \\
\hline & Negative $(n=57)$ & 39 & 18 & & \\
\hline
\end{tabular}


0.291-0.442), suggesting that this method was not suitable for screening purpose. The AUC $(0.819,95 \%$ CI: 0.7700.868) showed the reliability of this ELISA method. In addition, the similar sensitivities observed in sputum smear positive and negative patients suggested that this ELISA method may be suitable for the serological diagnosis of sputum smear negative individuals. Since sandwich ELISA is a rapid, simple and very common test used by many laboratories and laboratory staff [53], it should prove feasible and useful in resource-limited settings.

However, we did not include subsets of patients infected with HIV/TB [54], indicating that the clinical value of this ELISA method for a HIV-endemic population remains unknown. Moreover, this study involved only a few specific populations from hospital settings. Therefore, further studies in different and more extensive populations are necessary to evaluate the power of this test for the diagnosis of TB.

\section{Conclusions}

Using a combination of genetic engineering with SELEX and rabbit immunization, we developed a novel sandwich ELISA based on an anti-MPT64 antibody aptamer. Clinical validation showed that this ELISA method was a reliable test for the serological diagnosis of PTB and could be used especially for diagnostic purposes. However, this ELISA method could also be suitable for serological diagnosis of sputum smear negative populations.

\section{Competing interests}

The authors declare that they have no competing interests.

\section{Acknowledgments}

This work was supported by the Ministry of Science and Technology of the People's Republic of China (No. 2012ZX10003002-008), and the Science and Technology Commission of Shanghai Municipality, Shanghai, P. R. China (No. 10411955100 and No. 11ZR1430200).

\section{Author details}

'Department of Medical Laboratory, Changzhou Tumor Hospital Soochow University, Changzhou 213001, China. ${ }^{2}$ Shanghai Key Laboratory of Tuberculosis, Shanghai Pulmonary Hospital, Tongji University School of Medicine, Shanghai 200433, China. ${ }^{3}$ Department of Respiratory Medicine, Shanghai Pulmonary Hospital, Tongji University School of Medicine, Shanghai 200433, China. ${ }^{4}$ Shanghai Key Laboratory of Tuberculosis, Shanghai Pulmonary Hospital, Tongji University School of Medicine, No. 507 Zhengmin Rd, Shanghai 200433, People's Republic of China.

\section{Authors' contributions}

CTZ, ZYH, LHQ and JML designed the study. CTZ, HY, ZHL, RJZ and LHQ performed the experiments. CTZ, JML and $Y L$ performed the statistical analysis. CTZ, LHQ and YL wrote the manuscript. JML, HY and ZYH provided valuable insight for revising the manuscript. All authors contributed to the study and have read and approved the final manuscript. ZYH is the guarantor.

Received: 2 January 2012 Accepted: 20 April 2012 Published: 20 April 2012

\section{References}

1. World Health Organisation. Global tuberculosis control:WHO Report 2011. Geneva; 2011.
2. Aziz MA, Wright A: The World Health Organization/International Union Against Tuberculosis and Lung Disease Global Project on Surveillance for Anti-Tuberculosis Drug Resistance: a model for other infectious diseases. Clin Infect Dis 2005, 41(Suppl 4):S258-S262.

3. Gandhi NR, Moll A, Sturm AW, Pawinski R, Govender T, Lalloo U, Zeller K, Andrews J, Friedland G: Extensively drug-resistant tuberculosis as a cause of death in patients co-infected with tuberculosis and HIV in a rural area of South Africa. Lancet 2006, 368(9547):1575-1580.

4. Raviglione MC, Narain JP, Kochi A: HIV-associated tuberculosis in developing countries: clinical features, diagnosis, and treatment. Bull World Health Organ 1992, 70(4):515-526.

5. Pevzner ES, Vandebriel G, Lowrance DW, Gasana M, Finlay A: Evaluation of the rapid scale-up of collaborative TB/HIV activities in TB facilities in Rwanda, 2005-2009. BMC Public Health, 11:550.

6. Sandgren A, Strong M, Muthukrishnan P, Weiner BK, Church GM, Murray MB: Tuberculosis drug resistance mutation database. PLoS Med 2009, 6(2):e2.

7. Rasanathan K, Sivasankara Kurup A, Jaramillo E, Lonnroth K: The social determinants of health: key to global tuberculosis control. Int I Tuberc Lung Dis 2011, 15(Suppl 2):S30-S36.

8. Roche PW, Winter N, Triccas JA, Feng CG, Britton WJ: Expression of Mycobacterium tuberculosis MPT64 in recombinant Myco. smegmatis: purification, immunogenicity and application to skin tests for tuberculosis. Clin Exp Immunol 1996, 103(2):226-232.

9. Harboe M, Nagai S, Patarroyo ME, Torres ML, Ramirez C, Cruz N: Properties of proteins MPB64, MPB70, and MPB80 of Mycobacterium bovis BCG. Infect Immun 1986, 52(1):293-302.

10. Goldhofer W, Kreienberg R, Kutzner J, Lemmel EM: Influence of x-rays on the B- and T-cells in the spleen of mice and their reaction on mitogenetic substances (author's transl). Strahlentherapie 1979, 155 (4):277-283.

11. Chaudhary M, Gupta S, Khare S, Lal S: Diagnosis of tuberculosis in an era of HIV pandemic: a review of current status and future prospects. Indian J Med Microbiol 2010, 28(4):281-289.

12. Christy KG Jr, LaTart DB: Osterhoudt HW: Modifications for SDS-PAGE of proteins. Biotechniques 1989, 7(7):692-693.

13. Carroll MW, Moss B: E. coli beta-glucuronidase (GUS) as a marker for recombinant vaccinia viruses. Biotechniques 1995, 19(3):352-354, 356.

14. Kruger NJ: The Bradford method for protein quantitation. Methods Mol Biol 1994, 32:9-15.

15. Li H, Ulstrup JC, Jonassen TO, Melby K, Nagai S, Harboe M: Evidence for absence of the MPB64 gene in some substrains of Mycobacterium bovis BCG. Infect Immun 1993, 61(5):1730-1734.

16. Roche PW, Triccas JA, Avery DT, Fifis T, Billman-Jacobe H, Britton WJ: Differential T cell responses to mycobacteria-secreted proteins distinguish vaccination with bacille Calmette-Guerin from infection with Mycobacterium tuberculosis. J Infect Dis 1994, 170(5):1326-1330.

17. Oettinger T, Andersen AB: Cloning and B-cell-epitope mapping of MPT64 from Mycobacterium tuberculosis H37Rv. Infect Immun 1994, 62(5): 2058-2064.

18. Abe C, Hirano K, Tomiyama T: Simple and rapid identification of the Mycobacterium tuberculosis complex by immunochromatographic assay using anti-MPB64 monoclonal antibodies. J Clin Microbiol 1999, 37 (11):3693-3697.

19. Nakamura RM, Velmonte MA, Kawajiri K, Ang CF, Frias RA, Mendoza MT, Montoya JC, Honda I, Haga S, Toida I: MPB64 mycobacterial antigen: a new skin-test reagent through patch method for rapid diagnosis of active tuberculosis. Int J Tuberc Lung Dis 1998, 2(7):541-546.

20. Nakamura RM, Einck L, Velmonte MA, Kawajiri K, Ang CF, Delasllagas CE, Nacy CA: Detection of active tuberculosis by an MPB-64 transdermal patch: a field study. Scand J Infect Dis 2001, 33(6):405-407.

21. Ellington $A D$, Szostak JW: In vitro selection of RNA molecules that bind specific ligands. Nature 1990, 346(6287):818-822.

22. Tuerk C, Gold L: Systematic evolution of ligands by exponential enrichment: RNA ligands to bacteriophage T4 DNA polymerase. Science 1990, 249(4968):505-510.

23. Shangguan D, Li Y, Tang Z, Cao ZC, Chen HW, Mallikaratchy P, Sefah K, Yang CJ, Tan W: Aptamers evolved from live cells as effective molecular probes for cancer study. Proc Natl Acad Sci U S A 2006, 103(32):11838-11843.

24. Daniels DA, Chen H, Hicke BJ, Swiderek KM, Gold L: A tenascin-C aptamer identified by tumor cell SELEX: systematic evolution of ligands by 
exponential enrichment. Proc Natl Acad Sci U S A 2003, 100(26): 15416-15421.

25. Ohuchi SP, Ohtsu T, Nakamura Y: Selection of RNA aptamers against recombinant transforming growth factor-beta type III receptor displayed on cell surface. Biochimie 2006, 88(7):897-904.

26. Paul A, Avci-Adali M, Ziemer G, Wendel HP: Streptavidin-coated magnetic beads for DNA strand separation implicate a multitude of problems during cell-SELEX. Oligonucleotides 2009, 19(3):243-254.

27. Shi H, Tang Z, Kim Y, Nie H, Huang YF, He X, Deng K, Wang K, Tan W: In vivo fluorescence imaging of tumors using molecular aptamers generated by cell-SELEX. Chem Asian J 2010, 5(10):2209-2213.

28. Stoltenburg R, Reinemann C, Strehlitz B: FluMag-SELEX as an advantageous method for DNA aptamer selection. Anal Bioanal Chem 2005, 383(1):83-91.

29. Drabovich AP, Berezovski M, Okhonin V, Krylov SN: Selection of smart aptamers by methods of kinetic capillary electrophoresis. Anal Chem 2006, 78(9):3171-3178.

30. Berezovski MV, Musheev MU, Drabovich AP, Jitkova JV, Krylov SN: NonSELEX: selection of aptamers without intermediate amplification of candidate oligonucleotides. Nat Protoc 2006, 1(3):1359-1369.

31. Berezovski M, Musheev M, Drabovich A, Krylov SN: Non-SELEX selection of aptamers. J Am Chem Soc 2006, 128(5):1410-1411.

32. Dwivedi HP, Smiley RD, Jaykus LA: Selection and characterization of DNA aptamers with binding selectivity to Campylobacter jejuni using whole-cell SELEX. Appl Microbiol Biotechnol 2010, 87(6):2323-2334.

33. Huang CJ, Lin HI, Shiesh SC, Lee GB: Integrated microfluidic system for rapid screening of CRP aptamers utilizing systematic evolution of ligands by exponential enrichment (SELEX). Biosens Bioelectron 2010, 25 (7):1761-1766

34. Li S, Xu H, Ding H, Huang Y, Cao X, Yang G, Li J, Xie Z, Meng Y, Li X, et al: Identification of an aptamer targeting hnRNP A1 by tissue slide-based SELEX. J Pathol 2009, 218(3):327-336.

35. Tok JB, Fischer NO: Single microbead SELEX for efficient ssDNA aptamer generation against botulinum neurotoxin. Chem Commun (Camb)2008, 28 (16):1883-1885

36. Tanaka Y, Akagi K, Nakamura Y, Kozu T: RNA aptamers targeting the carboxyl terminus of KRAS oncoprotein generated by an improved SELEX with isothermal RNA amplification. Oligonucleotides 2007, 17(1): $12-21$.

37. Burke DH, Gold L: RNA aptamers to the adenosine moiety of S-adenosyl methionine: structural inferences from variations on a theme and the reproducibility of SELEX. Nucleic Acids Res 1997, 25(10):2020-2024.

38. Dastjerdi K, Tabar GH, Dehghani H, Haghparast A: Generation of an enriched pool of DNA aptamers for an HER2-overexpressing cell line selected by Cell SELEX. Biotechnol Appl Biochem 2011, 58(4):226-230.

39. Ireson CR, Kelland LR: Discovery and development of anticancer aptamers. Mol Cancer Ther 2006, 5(12):2957-2962.

40. Lupold SE, Hicke BJ, Lin Y, Coffey DS: Identification and characterization of nuclease-stabilized RNA molecules that bind human prostate cancer cells via the prostate-specific membrane antigen. Cancer Res 2002, 62 (14):4029-4033.

41. Guo KT, SchAfer R, Paul A, Gerber A, Ziemer G, Wendel HP: A new technique for the isolation and surface immobilization of mesenchymal stem cells from whole bone marrow using high-specific DNA aptamers. Stem Cells 2006, 24(10):2220-2231

42. Kunii T, Ogura S, Mie M, Kobatake E: Selection of DNA aptamers recognizing small cell lung cancer using living cell-SELEX. Analyst 2011, 136(7):1310-1312.

43. Zueva E, Rubio LI, Duconge F, Tavitian B: Metastasis-focused cell-based SELEX generates aptamers inhibiting cell migration and invasion. Int $J$ Cancer 2011, 128(4):797-804.

44. Cerchia L, Duconge F, Pestourie C, Boulay J, Aissouni Y, Gombert K, Tavitian $B$, de Franciscis $V$, Libri D: Neutralizing aptamers from whole-cell SELEX inhibit the RET receptor tyrosine kinase. PLOS Biol 2005, 3(4):e123.

45. Shamah SM, Healy JM, Cload ST: Complex target SELEX. Acc Chem Res 2008, 41(1):130-138

46. Berezovski MV, Lechmann M, Musheev MU, Mak TW, Krylov SN: Aptamer-facilitated biomarker discovery (AptaBiD). J Am Chem Soc 2008, 130(28):9137-9143.
47. Cheng C, Dong J, Yao L, Chen A, Jia R, Huan L, Guo J, Shu Y, Zhang Z: Potent inhibition of human influenza H5N1 virus by oligonucleotides derived by SELEX. Biochem Biophys Res Commun 2008, 366(3):670-674.

48. Guo KT, Ziemer G, Paul A, Wendel HP: CELL-SELEX: Novel perspectives of aptamer-based therapeutics. Int J Mol Sci 2008, 9(4):668-678.

49. Dua P, Kim S, Lee DK: Patents on SELEX and therapeutic aptamers. Recent Pat DNA Gene Seq 2008, 2(3):172-186.

50. Chen F, Zhou J, Luo F, Mohammed AB, Zhang XL: Aptamer from whole-bacterium SELEX as new therapeutic reagent against virulent Mycobacterium tuberculosis. Biochem Biophys Res Commun 2007, 357 (3):743-748

51. Vavvas D, D'Amico DJ: Pegaptanib (Macugen): treating neovascular age-related macular degeneration and current role in clinical practice. Ophthalmol Clin North Am 2006, 19(3):353-360.

52. Ulrich H, Trujillo CA, Nery AA, Alves JM, Majumder P, Resende RR, Martins $\mathrm{AH}$ : DNA and RNA aptamers: from tools for basic research towards therapeutic applications. Comb Chem High Throughput Screen 2006, 9 (8):619-632.

53. Leng SX, McElhaney JE, Walston JD, Xie D, Fedarko NS, Kuchel GA: ELISA and multiplex technologies for cytokine measurement in inflammation and aging research. J Gerontol A Biol Sci Med Sci 2008, 63(8):879-884.

54. Wanchu A: Advances in serology for diagnosing TB in the HIV infected. Indian J Chest Dis Allied Sci 2005, 47(1):31-37.

doi:10.1186/1471-2334-12-96

Cite this article as: Zhu et al.: Evaluation of the clinical value of ELISA based on MPT64 antibody aptamer for serological diagnosis of pulmonary tuberculosis. BMC Infectious Diseases 2012 12:96.

\section{Submit your next manuscript to BioMed Central and take full advantage of:}

- Convenient online submission

- Thorough peer review

- No space constraints or color figure charges

- Immediate publication on acceptance

- Inclusion in PubMed, CAS, Scopus and Google Scholar

- Research which is freely available for redistribution 